\title{
KEPERCAYAAN KEPADA KEKUATAN GAIB DALAM MANTRA MASYARAKAT MUSLIM BANTEN
}

\author{
Ayatullah Humaeni \\ Fakultas Ushuluddin dan Dakwah IAIN "Sultan Maulana Hasanuddin" Banten \\ Jalan Raya Anyer KM.21 Cibaru PO BOX 09 Anyer Banten \\ email: ayataditya@yahoo.com
}

\begin{abstract}
This article discusses various forms, functions, and meanings of mantra (magical formula) of Bantenese. How Bantenese understands mantra, what kinds of mantra used, and how Bantenese make use of various kinds of mantra in their life become three main focuses. It is the result of a field research using ethnographic method with the descriptive qualitative design based on anthropological perspective. To analyze the data, structural-functional approach is employed. Library research, participant-observation, and in depth interview are used to collect the data. The mantra tradition in Banten is a part of verbal folklore. Mantra is a tribal sacred prayer containing supernatural powers. The Bantenese mantra is a cultural product of the syncretic elements between local belief and religious traditions. For Bantenese, mantra is one of oral tradition treasures integrated to other cultural treasures. Its existence is still needed by Bantenese up to the present. In certain cases, the tradition of Bantenese mantra is an alternative of the traditional social institution when the formal institution is no longer able to accommodate their interests and practical needs. The use mantra for various purposes becomes a portrait of the pragmatical life style of Bantenese who still believe in magical powers.
\end{abstract}

Artikel ini mengkaji berbagai bentuk, fungsi dan makna mantra pada masyarakat Banten. Bagaimana masyarakat Banten memaknai mantra, jenis mantra apa saja yang digunakan oleh masyarakat Banten, dan bagaimana masyarakat Banten memanfaatkan mantra dalam kehidupan mereka menjadi tiga fokus 
utama dalam artikel ini. Tulisan ini merupakan hasil penelitian lapangan dengan menggunakan metode ethnografi yang bersifat deskriptif kualitatif dengan pendekatan antropologis. Dalam menganalisa data, peneliti menggunakan pendekatan fungsional-struktural. Metode yang digunakan untuk mengumpulkan data adalah kajian pustaka, observasi, dan wawancara mendalam. Tradisi mantra di Banten merupakan bagian dari tradisi lisan. Mantra merupakan do'a sakral kesukuan yang mengandung kekuatan gaib. Mantra Banten ini merupakan produk budaya yang bersifat sinkretik antara kepercayaan lokal dan tradisi agama. Bagi orang Banten, mantra merupakan salah satu khazanah tradisi lisan yang integral dengan khazanah budaya lainnya. Eksistensinya masih dibutuhkan oleh masyarakat Banten sampai saat ini. Dalam batas tertentu, tradisi mantra Banten merupakan alternatif pranata sosial tradisional ketika pranata formal tidak mampu lagi mengakomodasi kepentingan dan kebutuhan praktis mereka. Pemanfaatan mantra untuk beragam tujuan ini menjadi potret pola kehidupan pragmatis masyarakat Banten yang masih mempercayai kekuatan magic.

Keywords: magic, mystics, socio religious, Banten

\section{Pendahuluan}

Mantra merupakan salah satu produk budaya yang hampir selalu muncul pada setiap budaya masyarakat dimanapun di dunia, terutama pada budaya masyarakat pre-literate. Keberadaan mantra juga pernah mewarnai kehidupan masyarakat di Nusantara, dan hingga kini keberadaan mantra dengan beragam karakteristik khasnya masih bisa kita temukan pada sebagian masyarakat Indonesia, tidak terkecuali di Banten.

Mantra sebagai elemen penting dalam praktek ilmu magic masih ditradisikan oleh sebagian masyarakat Banten, baik untuk tujuan positif maupun sebaliknya. Tingginya kepercayaan masyarakat Banten terhadap hal-hal yang bersifat supernatural, tidak saja menjadikan mantra magic masih survive di Banten hingga saat ini, tapi juga menjadi bukti kongkrit adanya kekayaan khazanah kebudayaan Banten yang belum banyak diteliti dan ditulis dalam karya yang bersifat ilmiah.

Reputasi Banten sebagai tempat bersemayamnya ilmu-ilmu magic sudah dikenal luas. Banyak orang di luar Banten, yang ketika menyebut Banten, konotasi yang muncul dalam pikiran mereka adalah sebuah daerah yang penuh dengan praktek dan ilmu magic. Oleh karena itu, seringkali ditemukan beberapa orang di luar Banten yang memiliki ilmu magic tertentu, menyatakan bahwa ilmu magic yang mereka miliki berasal dari daerah Banten. Hal ini 
lah yang memperkuat citra Banten sebagai pusat praktek magic. Tidak heran jika kemudian, banyak literatur dan hasil penelitian tentang Banten, sedikit banyak membahas tentang reputasi Banten sebagai the central spot of magical practices. Tradisi-Tradisi Islam di Indonesia menyebut Banten sebagai $a$ heaven of the occult sciences (Bruinessen, 1995: 176).

Berdasarkan penjelasan di atas, berbicara tentang mantra magic (magical formula) di Banten menjadi subjek yang menarik untuk dikaji karena beberapa alasan. Pertama, Banten sebagai sebuah daerah yang dikenal dengan praktik magicnya, tentu memiliki keanekaragaman mantra magic. Kedua, sebagian besar mantra yang tersebar dalam budaya masyarakat Banten hanya tersimpan dalam memori orang-orang tertentu, hanya sedikit orang yang mencatat tentang mantra magic yang mereka miliki atau mereka ketahui, hal ini dikhawatirkan akan punah oleh arus modernisasi yang lebih dominan, sehingga budaya ini kalau tidak segera ditulis dan didokumentasikan niscaya akan hilang dan tidak berbekas. Ketiga, beragam mantra hingga saat ini masih dimanfaatkan oleh masyarakat Banten untuk berbagai keperluan, terutama untuk mengobati penyakit. Dan banyak bukti empiris yang menyatakan besarnya pengaruh dan manfaat magic bagi masyarakat. Berbagai jenis mantra ini, jika ditulis dan dibukukan, bukan hanya bisa dijadikan bahan rujukan bagi penelitian dan bagi pengetahuan tentang budaya dan tradisi lokal, tapi juga bisa terus ditradisikan oleh generasi berikutnya yang tertarik untuk mendalami ilmu magic demi kepentingan masyarakat. Artikel ini mencoba menjelaskan beberapa rumusan masalah yaitu bagaimana masyarakat Serang Banten memaknai dan memperlakukan mantra magic? Jenis mantra magic seperti apa yang digunakan oleh masyarakat Serang Banten? Bagaimana fungsi mantra bagi masyarakat Banten?

Penelitian ini menggunakan metode ethnografi yang bersifat deskriptif kualitatif dengan menggunakan pendekatan antropologis. Dalam menganalisa data, peneliti akan menggunakan pendekatan fungsional-struktural (structuralfunctional approach). Metode yang digunakan untuk mengumpulkan data adalah kajian pustaka, observasi, dan wawancara mendalam.

\section{Konteks Sosial Budaya Masyarakat Banten}

Banten adalah salah satu provinsi yang terletak di bagian paling Barat pulau Jawa dan termasuk salah satu provinsi paling muda di Indonesia. Banten menjadi provinsi sejak tanggal 22 Oktober 2000 dengan Undang-Undang nomor 23 tahun 2000 pada tanggal 17 Oktober 2000. Saat ini, Banten terdiri dari 
empat kabupaten yaitu Kabupaten Serang, Pandeglang, Lebak, dan Tangerang, dan empat kota, yaitu Kota Serang, Kota Cilegon, Kota Tangerang, dan Kota Tangerang Selatan.

Berbicara tentang masyarakat Banten tidak dapat dilepaskan dari konteks sejarah bagaimana masyarakat ini terbentuk. Dinamika sejarah masa lalu Banten sudah membentuk masyarakat Banten yang multi-etnis dan multibahasa dan budaya yang dalam perjalanan waktu berbaur secara intensif dan membentuk satu identitas, satu budaya, dan satu masyarakat yaitu masyarakat atau etnis Banten.

Dalam berbagai catatan sejarah, tercatat bahwa masyarakat Banten sudah mengalami kontaks dan komunikasi yang intens dengan masyarakat dari berbagai etnis dan bangsa. Interaksi masyarakat Banten dengan dunia luar diduga sudah dilakukan sejak abad pertama masehi. Hal ini dikarenakan Banten berada di jalur pelayaran internasional yang sering dilewati dan dikunjungi oleh bangsa lain seperti India, Cina, dan Eropa. Bahkan, pada abad ke-7 M, Banten sudah menjadi salah satu tempat tujuan para pedagang dari berbagai negara dan menjadi pelabuhan yang ramai dikunjungi oleh para pedagang internasional (Michrob dan Chudari, 2011: 54). Penduduk dari berbagai wilayah di Nusantara seperti Peureulak, Demak, Cirebon dan lain sebagainya juga banyak yang berkunjung dan berniaga di pelabuhan Banten.

Sebagaimana lazimnya masyarakat di daerah lain di Nusantara, masyarakat Banten juga pernah mengalami berbagai fase perkembangan sejarah dengan beragam corak dan karakteristik budaya dan kepercayaannya yang berbedabeda antara satu fase dengan fase berikutnya. Dalam beberapa catatan sejarah, perkembangan masyarakat Banten di awali dengan masa pra-sejarah yang terdiri dari tiga tingkatan kehidupan, yaitu masa berburu dan mengumpulkan makananan, masa bercocok tanam, dan masa perundagian (kemahiran teknik), masa Hindu-Budha, masa Kesultanan Islam Banten, masa Kolonial, masa kemerdekaan, dan masa Banten menjadi provinsi hingga saat ini (Michrab dan Chudari, 2011: 55).

Dalam konteks masyarakat Banten, interaksi yang intens antara budaya masyarakat pribumi Banten dengan beragam kebudayaan dunia, khususnya kebudayaan Islam yang dibawa oleh para pedagang dari berbagai negara pada masa kesultanan, membawa babak baru bagi kebudayaan masyarakat Banten. Dalam berbagai catatan sejarah tercatat bahwa masuknya Islam ke Banten dan berdirinya kesultanan Islam Banten pada tahun 1552 menjadikan Banten sebagai salah satu pusat peradaban Islam yang baru di Nusantara. Penetrasi 
Islam oleh para 'pendakwah' dan didukung oleh otoritas penguasa (Sultan) terhadap tradisi dan kebudayaan lokal masyarakat Banten, hampir secara sempurna meresap dalam berbagai ritual, upacara keagamaan, serta warisan keagamaan di Banten.

Meskipun Islam menjadi simbol peradaban baru bagi masyarakat Banten saat itu, namun para Sultan Banten tidak serta merta menghapus jejak tradisi dan budaya lokal Banten yang sudah ada jauh sebelum Islam masuk dan berkembang. Indikasi bahwa penguasa Banten saat itu masih menghargai dan menghormati tradisi dan budaya lokal adalah cerita dalam 'Sadjarah Banten' yang menyatakan bahwa Sultan Ageng Tirtayasa, sejak belia dan masih menjabat sebagai Sultan Muda, dikenal sebagai putra bangsawan yang sangat menyukai kebudayaan; bahkan ia seringkali terlibat aktif dalam beberapa tradisi permainan rakyat Banten seperti permainan raket (semacam wayang wong), dedewaan, sasaptoan, dan berbagai tradisi lokal lainnya (Tjandrasasmita, 2011: 29). Hal ini mengindikasikan bahwa Sultan Banten, yang dianggap sebagai pemimpin agama, ulama, bahkan dianggap sebagai wali, tidak pernah berusaha menghapus jejak tradisi dan budaya lokal yang dianggap tidak merusak akidah umat Islam. Artinya bahwa bagi masyarakat Banten, ketaatan dalam beragama (Islam) tidak mesti menghapus identitas kultural masyarakat Banten.

Sikap akomodatif Kesultanan Banten terhadap budaya lokal juga nampak pada berbagai peninggalan budaya material yang sebagian masih dapat disaksikan bentuknya saat ini. Berbagai peninggalan budaya ini merefleksikan kuatnya interaksi dan akulturasi Islam dan budaya lokal dalam beragam bentuk pada masa kesultanan. Sebagai contoh, bentuk masjid Agung Banten yang beratap tumpang, berbatu tebal, dengan tiang saka, kolam taharah, dan sebagainya betul-betul menunjukkan karakteristik arsitektural lokal, sementara esensi Islam terletak pada 'ruh' fungsi masjidnya sendiri sebagai tempat beribadah kepada Tuhan dan keberadaan mihrab dan mimbar untuk khotbah (Ambary, 1996: 119).

Selain pada bangunan masjid, bentuk akulturasi Islam dan budaya lokal pada masa itu juga bisa dilihat dari beberapa peninggalan sejarah dan budaya Kesultanan Banten lainnya yang tidak menghapus simbolisasi agama yang dianut oleh masyarakat Banten pra-Islam. Danau buatan Tasik Ardi yang dibangun untuk mengelola penyediaan air bersih bagi istana, irigasi, dan keperluan rakyat, misalnya, secara fisik sarat dengan simbol-simbol arsitektur kosmologis Hindu, yaitu menyerupai sebuah pulau di tengah danau dengan 
Gapura Bentar dan Paduraksa serta bangunan untuk istirahat sultan. Begitu juga dengan arsitektur dua pintu gerbang Bentar dan Paduraksa sebagai ambang masuk mushala di Keraton Kaibon (Ambary, 1996: 120).

Sikap akomodatif dan toleransi para penguasa Banten pada masa itu terhadap keberadaan tradisi dan budaya lokal masyarakat Banten sepertinya menjadi salah satu alasan mengapa Islam dapat diterima secara luas oleh masyarakat Banten dan berkembang cukup pesat pada masa itu. Interkasi Islam terhadap budaya lokal dan pra-Islam di Banten merupakan fenomena yang nyaris ditemui pada setiap segmen budaya di Banten (Ambary, 1996: 119-120).

Sikap toleransi Islam terhadap agama dan kepercayaan masyarakat Banten pra-Islam juga bisa ditunjukkan lewat berbagai peninggalan budaya beberapa tempat atau situs pemujaan masyarakat pra-Islam seperti situs Lebak Sibedug, situs Lebak Kosala, dan beberapa tempat yang lain yang banyak ditemukan di daerah Banten Selatan. Meskipun masyarakat di sekitar tempat tersebut sudah beragama Islam, namun penghormatan dan pengagungan tempat-tempat keramat tersebut masih berlangsung hingga saat ini.

Praktik-praktik magic masyarakat Banten pra-Islam mendapat legitimasi pentransmisian dan pewarisannya sehingga masih diyakini dan dipraktikkan oleh masyarakat Banten hingga saat ini karena adanya ayat-ayat yang menjelaskan keberadaan dunia supernatural dan dunia gaib baik dalam proses penciptaan manusia dan dalam proses kehidupan manusia. Bahkan Tuhan sendiripun dalam Islam dianggap sebagai dzat yang Maha Gaib, yang tidak bisa dilihat oleh indera manusia. Begitu juga malaikat, jin, dan makhluk-makhluk ciptaan Allah yang lain yang dianggap mewakili eksistensi keberadaan dunia lain yang abstrak yang tidak terjangkau oleh penelitian empiris.

Penggunaan ayat-ayat al Quran sebagai sumber kekuatan magic dalam dunia Muslim juga diakui oleh Bowen yang meneliti masyarakat Gayo. Ia berpendapat bahwa kitab suci al Quran dipahami sebagai ucapan atau kalimat yang powerful (memiliki kekuatan magic). Masyarakat muslim di Isak Gayo mengkaji dan membaca al Quran tidak hanya sekedar untuk memperoleh pahala dan ilmu, tetapi juga kekuatan supernatural yang bersumber darinya. Mereka berkeyakinan, dengan membaca ayat-ayat tertentu yang dianggap memiliki daya magic, si pembaca akan mendapatkan karunia Tuhan berupa efek atau kekuatan magic tertentu seperti yang terkandung dalam ayat-ayat spesifik tersebut. Kondisi ini, menurutnya tidak hanya terjadi pada masyarakat Muslim Isak Gayo, tetapi juga masyarakat Muslim di Sumatera, Pakistan, atau 
Mesir (Bowen, 1993: 94-96). Begitu pun sebaliknya, budaya lokal juga bisa menjadi alat legitimasi bagi Islam. Dalam hal ini, kepercayaan masyarakat Banten pra-Islam tentang adanya kekuatan adikodrati dan keberadaan alam gaib dalam alam pikiran mereka yang diwujudkan dalam berbagai praktik magic dan beragam kepercayaan terhadap mantra juga menjadi semacam penguat keyakinan masyarakat tentang kebenaran Islam yang tidak hanya mencakup urusan-urusan manusia yang bersifat duniawi (the Profane) tetapi juga yang bersifat sakral dan ukhrowi (the sacred). Budaya lokal dalam kepercayaan masyarakat Banten pra-Islam tentang dunia gaib dan makhluk gaib menjadi semacam alat legitimasi dalam memperkuat penetrasi Islam dalam setiap aspek kehidupan masyarakat Banten karena Islam dianggap mampu mengakomodir dimensi magic dalam ruang pemikiran dan keyakinan mereka.

Dalam konteks kepercayaan dan praktik magic di masyarakat Banten, banyak sekali ditemukan adanya sikap adaptif dan akulturatif Islam terhadap budaya lokal. Dalam bacaan atau mantra magic, misalnya, peneliti menemukan ratusan bahkan mungkin ribuan mantra dengan beragam fungsinya yang digunakan oleh masyarakat Banten merupakan campuran eklektik dari ayatayat al Quran dan jangjawokan (bahasa lokal, baik Sunda maupun Jawa) yang seringkali isinya mengandung unsur-unsur Hindu dan kepercayaan animistis lainnya. Penyebutan nama Nyi Pohaci (Dewi Sri dalam kepercayaan Hindu), Ki Buyut Rintik, Ki Depa (arwah leluhur) dan lain sebagainya yang dibalut dengan bacaan atau kalimat-kalimat dari al Quran menunjukkan adanya sikap akulturatif Islam pada masyarakat Banten terhadap budaya dan tradisi lokal yang sebelumnya sudah ada jauh sebelum Islam masuk.

\section{Mantra dalam Kepercayaan Masyarakat Banten}

Mantra merupakan ragam puisi lisan yang cenderung terlupakan karena hidup dalam komunitas tradisional yang marginal. Ia juga mencitrakan kondisi masyarakat yang cenderung bernuansa 'tribal'. Berkaitan dengan hal ini, dijelaskan juga adanya Sabuk Mangir dan Jaran Goyang Masyarakat Suku Using Banyuwangi menjelaskan bahwa mantra merupakan doa sakral yang mengandung magic dan berkekuatan gaib yang dimanfaatkan sebagai sarana untuk membantu mempermudah dalam meraih sesuatu dengan jalan pintas (Saputra, 2007: 9).

Istilah mantra berasal dari bahasa Sanskerta yang terdiri dari dua suku kata 'man' yang berarti pikiran dan 'tra' yang bermakna penyampaian. Dari makna etimologi ini, mantra dapat diartikan sebagai media penyampaian 
formula-formula mental ke dalam pikiran. Makna ini diambil dari penjelasan A.C. Bhaktivedanta Swami Prabuphada yang menyatakan bahwa "the Sanskrit word mantra is a combination of two syillables, man and tra. Man means 'mind', and tra means 'deliverance. Therefore, a mantra is that which delivers you from mental concoction, from hovering on the mental plane" (Hartarta, 2010: ix). Sedangkan Budya Pradipta menyatakan bahwa mantra berasal dari kata man/manas dan tra/tri yang berarti 'berpikir atau melindungi, melindungi pikiran dari gangguan jahat' (Pradipta, 2003: 2; Hartarta, 2010: 36). Jadi mantra tidak selalu bersifat negatif, apalagi ilmu hitam.

Dari pengertian di atas, nampak bahwa mantra lebih bermakna positif, bukan untuk tujuan jahat. Senada dengan pengertian di atas, T. Plattes, sebagaimana dikutip oleh Haroen Daod, berpendapat bahwa kata 'matra' berasal daripada bahasa Sanskrit, yaitu 'mantra' atau 'manir' yang merujuk pada ucapan-ucapan kudus dalam kitab-kitab suci Veda, mengandung unsur magic dan jampi serapah. Mantra menjadi amalan yang melingkupi seluruh hidup masyarakat Hindu, terutama untuk tujuan kebaikan (Daod, 2004: xiii). Dari pengertian ini, dapat dimaknai bahwa bagi umat Hindu, mantra merupakan 'semacam wahyu' yang memiliki nilai kudus atau suci serta mengandung unsur magic dan menjadi petunjuk hidup bagi kehidupan umat Hindu.

Namun demikian, bukan berarti bahwa mantra bermula dari kepercayaan agama Hindu yang telah diakomodasi dan mengalami asimilasi dan akulturasi pada agama-agama dan kepercayaan-kepercayaan yang lain. Karena berdasarkan hasil-hasil penelitian beberapa ahli antropologi dan sosiologi, keberadaan mantra sudah ada sejak zaman animisme dan menjadi bagian penting dari aktifitas religius masyarakat primitif.

Dalam kamus bahasa Jawa, dijelaskan bahwa kata mantra berasal dari kata man yang berarti nggagas (Bhs.Jawa) dan tra yang merupakan sufik pembentuk kata benda. Mantra berarti wohing penggagas (Bhs.Jawa) dan dalam bahasa Indonesia diterjemahkan sebagai hasil dari daya pikir (Hartarta, 2010: 38). Dalam pengertian ini, jelas bahwa mantra merupakan hasil cipta dari kekuatan dan daya pikir manusia. Pengertian mantra dalam masyarakat Jawa bergantung pada penggunaan Bahasanya. Bagi bahasa Jawa Kuno, arti mantra hampir sama dengan makna dalam bahasa Sanskrit, yaitu memberi tekanan kepada teks atau ungkapan yang suci dan nyanyian yang berbentuk puji-pujian kepada tuhan (Daod, 2004: xvi).

Berkaitan dengan kekuatan gaib yang dihasilkan dari mantra, Malinowski berpendapat bahwa mantra merupakan bagian paling penting dari magic. 
Mantra adalah bagian magic yang bersifat gaib, yang menyatu dalam ritual magic, yang diketahui hanya oleh si praktisi magic. Bagi masyarakat pribumi, ilmu magic sama artinya dengan ilmu mantra, dan dalam sebuah analisis dari suatu tindakan sihir akan selalu ditemukan bahwa ritual berpusat diseputar ucapan mantra. Formula magic atau mantra selalu menjadi inti dari performance magic (Malinowski, 1955: 74).

Definisi lain mantra sebagai perkataan atau ucapan yang dapat mendatangkan daya gaib atau susunan kata berunsur puisi yang dianggap mengandung kekuatan gaib dan biasanya diucapkan oleh dukun atau pawang untuk menandingi kekuatan gaib yang lain (Saputra, 2007: 95-96). Senada dengan definisi di atas, definisi lain juga memberikan definisi yang sama dengan tambahan bahwa mantra dapat mengandung tantangan atau kutukan terhadap suatu kekuatan gaib dan dapat berisi bujukan agar kekuatan gaib tersebut tidak berbuat yang merugikan. Sebagai magic kata (word magic), mantra dimaksudkan untuk memperoleh suatu kekuatan bagi keuntungan orang yang mengucapkannya (Sudjiman, 1990: 51).

Istilah mantra sangat akrab dikenal dalam lingkungan agama dan kepercayaan Hindu dan Budha. Dua agama tersebut menjadikan mantra sebagai sarana peribadatan, mantra dianggap sebagai teks suci (Yale, 2003:3). Lebih lanjut, dinyatakan bahwa dalam tradisi Tantra, Mantra berarti hasil dari kontemplasi (manana) lalu seseorang memeliharanya (trayate). Mantra diturunkan dari akar kata man yang berarti berfikir atau merenung dan mendapat sufiks (akhiran) tra yang berarti 'sebagai sarana berfikir atau merenung (an instrument of thought). Mantra dalam pengertian tradisi tantra sebagaimana dijelaskan oleh Yale mempunyai persamaan dalam tradisi Islam yaitu zikir dan wiridan sebagai sarana memusatkan pikiran dan hati untuk senantiasa mengingat Allah (Yale, 2003:4-5).

Dari penjelasan di atas nampak bahwa mantra tidak hanya digunakan untuk tujuan-tujuan yang baik dan positif seperti untuk keselamatan, kesembuhan penyakit, keberhasilan usaha dan karir, tapi juga dimanfaatkan untuk tujuan-tujuan yang jahat dan bisa mencelakakan orang lain seperti untuk membuat orang sakit, sulit mendapat keturunan, sulit dalam berjualan, bahkan ada mantra untuk membunuh seseorang.

Citra Banten sebagai wilayah religius dan sebagai pusat praktik ilmuilmu gaib (magic) sudah dikenal luas bukan hanya oleh masyarakat Banten pada khususnya, tapi juga oleh masyarakat Indonesia. Berbagai literatur dan hasil penelitian tentang Banten, sedikit banyak seringkali membahas tentang 
reputasi Banten sebagai the central spot of magical practices (Bruinessen, 1995: 176). Debus, ilmu dan praktik kekebalan atas api dan benda-benda tajam, adalah contoh paling kongkret dari tradisi magic di Banten yang sudah ada sejak zaman kesultanan sampai saat ini. Para guru atau syaikh debus dalam pertunjukannya melibatkan seluruh rangkaian praktek-praktek magic. Teknikteknik yang mereka gunakan menurut Martin van Bruinessen adalah suatu capuran antara magic Islam dan magic pra-Islam, formula-formula yang digunakan memasukan do'a-do'a Islam berbahasa Arab di samping formula-formula magic berbahasa Jawa dan Sunda (Bruinessen, 1995: 187-188).

Dalam konteks budaya Banten, mantra (magical formula) memiliki fungsi yang sangat penting bagi individu-individu yang memilki kepercayaan dan keyakinan tentang kekuatan gaib di dalam matra tersebut. Ada banyak ragam matra yang tersebar dan digunakan oleh masyarakat Banten. Dari sisi fungsi nya, magic dan matra ini ada yang digunakan untuk tujuan baik atau positif seperti untuk mengobati, untuk kekebalan dan keselamatan dan sebagainya, ada juga yang dimanfaatkan untuk tujuan jahat atau negatif seperti untuk mengguna-guna orang, menyantet atau meneluh seseorang supaya sakit atau bahkan mati. Ada juga ilmu magic dan mantra-mantra yang dipergunakan untuk pengasihan atau pelet.

Tradisi mantra di Banten merupakan bagian dari tradisi lisan (verbal folklore). Mantra merupakan doa sakral kesukuan yang mengandung magic dan berkekuatan gaib. Mantra Banten ini merupakan produk budaya yang bersifat sinkretik antara kepercayaan lokal dan tradisi agama. Bagi orang Banten, mantra merupakan salah satu khazanah budaya lisan yang integral dengan khazanah budaya lainnya. Eksistensinya masih dibutuhkan oleh masyarakat Banten sampai saat ini.

Di Banten, ketika mempelajari ilmu magic, banyak hal yang harus dilampaui oleh seorang pelaku magic. Berbagai jenis ritual, baik itu ritual puasa, tirakat (bertapa), ziarah di tempat-tempat keramat, wirid, dan lain sebagainya harus dilampaui oleh seseorang yang ingin menguasai jenis magic tertentu. Di samping itu, berbagai formula magic seperti mantra juga menjadi bagian penting dalam ritual penguasaan ilmu magic. Namun demikian, ada juga sebagian orang yang lebih tertarik untuk memiliki benda-benda magic saja seperti azimat, wafak, rajah dan lain sebagainya, ketimbang harus melakukan ritual magic tertentu yang membutuhkan keseriusan, ketekunan, kesabaran, dan konsentrasi tinggi dan membutuhan waktu yang lama. Sebagian orang percaya, hanya dengan memiliki benda-benda magic tersebut, mereka bisa 
memiliki kekuatan magic, atau paling tidak merasakan efek magic dari bendabenda magic tersebut. Oleh karena itu, di Banten, selain ada ritual-ritual dan mantra-mantra tertentu yang harus dijalani oleh seseorang yang ingin menguasai ilmu magic, ada juga benda-benda magic yang bisa langsung diminta kepada ahli magic, atau barangkali dengan ritual tertentu bisa didapatkan oleh seseorang untuk mendapatkan benda-benda magic tersebut.

Dalam konteks budaya Banten, mantra (magiccal formula) memiliki fungsi yang sangat penting bagi individu-individu yang memilki kepercayaan dan keyakinan tentang kekuatan gaib di dalam rangkaian matra tersebut. Ada banyak ragam matra yang tersebar dan digunakan oleh masyarakat Banten. Dari sisi fungsi nya, mantra magic ini ada yang digunakan untuk tujuan baik atau positif seperti untuk mengobati, untuk kekebalan dan keselamatan dan sebagainya, ada juga yang dimanfaatkan untuk tujuan jahat atau negatif seperti untuk mengguna-guna orang, menyantet atau meneluh seseorang supaya sakit atau bahkan mati. Ada juga mantra yang dipergunakan untuk pengasihan atau pelet.

Tradisi pemanfaatan mantra ini sudah cukup lama bertahan di Banten yang diturunkan secara turun temurun dan melalui tradisi lisan. Para dukun dan orang-orang yang dipandang memiliki kemampuan magic seperti wong pinter biasanya banyak yang menggunakan mantra-mantra dalam ritual magic mereka. Tidak jarang dukun-dukun yang sedang membacakan mantra tertentu, gesture tubuh dan mimik mukanya seolah-olah mereka sedang dalam keadaan dimasuki oleh makhluk gaib. Sehingga seolah-olah yang berbicara dan yang bertindak bukan dirinya, tetapi makhluk gaib yang masuk kedalam jasadnya. Hal ini barangkali dilakukan untuk meyakinkan pasien atau orang lain bahwa para dukun betul-betul bisa mempengaruhi, menguasai dan menundukan makhluk gaib sehingga makhluk-makhluk ini bisa dimintai bantuan untuk melakukan apa yang diinginkan oleh dukun tersebut dengan cara-cara magic.

\section{Dimensi Magi sebagai Simbol Pragmatisme dan Identitas Kultural Masyarakat Muslim Banten}

Tradisi mantra di Banten merupakan bagian dari tradisi lisan (verbal folklore) yang mengandung magic dan berkekuatan gaib. Mantra Banten ini merupakan produk budaya yang bersifat sinkretik antara kepercayaan lokal dan tradisi agama (Islam). Bagi orang Banten, mantra merupakan salah satu khazanah budaya lisan yang integral dengan khazanah budaya lainnya. Eksistensinya masih dibutuhkan oleh masyarakat Banten sampai saat ini. 
Tingginya kepercayaan masyarakat Banten terhadap hal-hal yang bersifat supernatural, tidak saja menjadikan mantra magic masih bertahan di Banten hingga saat ini, tapi juga menjadi bukti kongkrit adanya hubungan erat antara agama dan magic. Magi merupakan sebuah elemen yang ada dalam semua agama, walaupun nampaknya magic nampak paling dominan dalam tradisi agama yang berhubungan dengan masyarakat primitif (Angrosino, 2004: 122). Rudolf Otto, seorang ahli teologi, berpendapat bahwa semua sistem religi, kepercayaan dan agama di dunia berpusat kepada suatu konsep tentang hal yang gaib (mysterium) yang dianggap maha dahsyat (tremendum), dan keramat (sacer) oleh manusia (1936). (Otto, 1936: 77).

Penduduk Banten, sebagaimana pengamatan Snouck Hurgronje adalah 'masyarakat yang lebih taat dibandingkan masyarakat Jawa lainnya dalam melaksanakan kewajiban-kewajiban agama seperti puasa di bulan Ramadhan dan dalam membayar Zakat' (Bruinessen,1995: 246). Akan tetapi, ritual-ritual keagamaan mereka kadang-kadang terkontaminasi oleh aspek-aspek sinkretis yang berasal dari tradisi pra-Islam. Hal ini dapat dibuktikan dari beberapa praktik magic di pedesaan Banten yang seringkali menggunakan teknik-teknik dan formula-formula magic yang nampaknya bukan diambil dari sumber-sumber utama ajaran Islam, yakni al Quran dan Hadits. Penjelasan ini dapat dilacak dari banyak mantra yang menggunakan bahasa jangjawokan baik yang berbahasa Sunda, Jawa, atau bahasa Jawa Kuno yang kadang-kadang maknanya sangat sulit dipahamai dan seringkali makna dari mantra-mantra ini mengandung unsur-unsur animisme seperti kepercayaan atas roh-roh halus, jin-jin, roh-roh gaib nenek moyang dan makhluk gaib lainnya. Selanjutnya, mantra-mantra ini diislamisasi oleh para ahli magic dengan menambahkan lafadz-lafadz atau ayat-ayat al Quran tertentu pada mantra tersebut sehingga mantra-mantra tersebut seolah-olah mantra Islam.

Dalam batas tertentu, tradisi mantra Banten merupakan alternatif pranata sosial tradisional ketika pranata formal tidak mampu lagi mengakomodasi kepentingan mereka. Pemanfaatan mantra ini menjadi potret pola kehidupan pragmatis masyarakat Banten yang masih mempercayai hal-hal yang bersifat magic. Secara tipologis, formula magic di Banten terbagi dalam tiga jenis. Pertama adalah doa-doa yang diambil dari ayat-ayat al Quran maupun wiridan yang diambil dari Hadits, al Asma al Husna, dan lain sebagainya yang bersumber dari Islam yang diyakini memiliki efek dan daya magic. Kedua, mantra-mantra (jangjawokan) dalam bahasa Sunda, Jawa, atau Melayu yang diyakini memiliki pengaruh dan kekuatan magic. Ketiga adalah campuran eklektik dari doa-doa Islami dan mantra lokal. 
Kiai hikmah (ahli hikmah) di Banten umumnya lebih banyak menggunakan doa-doa, wiridan atau bacaan- bacaan tertentu yang di ambil dari al Quran, kitab-kitab hikmah atau dari bacaan al Asma al Husna yang dianggap memiliki nilai magic sebagai bacaan untuk diamalkan (dijadikan wiridan) oleh orang yang meminta ilmu magic, walaupun ada juga sebagian ahli hikmah yang juga menggunakan doa yang bercampur dengan mantra dalam bahasa lokal (jangjawokan). Hal ini dapat dilacak dari berbagai jenis formula magic yang peneliti peroleh dari beberapa ahli hikmah di lapangan. Namun demikian, Pendapat lainmenyatakan bahwa doa-doa yang tercampur dengan bahasa Jangjawokan, apa lagi yang menyebut-nyebut ruh-ruh leluhur, haram digunakan oleh seorang Muslim. Seorang Muslim hanya boleh menggunakan doa-doa yang bersumber dari al Quran dan hadits (Rahman, 2012: 77).

Dukun biasanya menggunakan mantra berbahasa Jawa atau Sunda, walaupun diantara mereka juga ada yang memberikan jenis wiridan atau amalan sebagaimana yang diberikan oleh ahli hikmah. Sebagian masyarakat Banten, terutama yang sudah sepuh (lanjut usia), juga masih banyak yang menggunakan mantra-mantra dari campuran ayat-ayat al Quran dan bahasa lokal (jangjawokan). Sebagian masyarakat berpendapat bahwa penggunaan mantra, walaupun menggunakan bahasa Jangjawokan, selama masih ada bacaan-bacaan al Qurannya, dan memintanya kepada Allah, tidak terbilang perbuatan syirik.

Mantra adalah bagian paling penting dari praktik magic. Mantra adalah bagian magic yang bersifat gaib (magic), yang diberikan dalam aktifitas magic dan hanya diketahui oleh praktisi atau ahli magic. Bagi para penduduk asli yang telah diteliti, ilmu magic berarti juga ilmu mantra, artinya bahwa orang yang ahli atau mengetahu mantra dia dapat dianggap sebagai dukun atau orang yang memiliki ilmu magic. Dari hasil analisisnya pada berbagai aksi tenung (witchcraft), akan selalu ditemukan bahwa pusat ritual akan berpusat pada mantra-mantra yang diucapkan. Menurutnya, formula magic (mantra) selalu menjadi 'the core of the magical performance' (Malinowski, 1955: 73).

Begitu juga di Banten, dalam setiap aktifitas magic pasti ada bacaanbacaan tertentu, baik itu berbentuk mantra maupun wiridan yang dibaca oleh ahli magic yang kadangkala maknanya tidak dipahami oleh orang biasa. Baik untuk mengobati penyakit maupun mengusir roh jahat ada doa-doa atau mantra-mantra tertentu yang dibacakan oleh ahli hikmah dan dukun yang diyakini mampu berpengaruh terhadap kondisi si pasien sesuai dengan tujuan yang diinginkan. 
Keyakinan dan kepercayaan masyarakat Muslim Banten terhadap mantra merefleksikan bahwa kepercayaan terhadap Yang Gaib merupakan bagian integral dari alam pikiran mistis masyarakat Banten. Dimensi magic yang masih bertahan dan diyakini dalam alam pikiran mistis masyarakat Muslim Banten juga bermakna bahwa mereka memiliki satu keyakinan bahwa makhlukmakhluk gaib dapat dikontrol, ditransformasi, dikuasai dan diperintah untuk memenuhi tujuan-tujuan pragmatis dan praktis manusia. Sepanjang manusia merasa memiliki keterbatasan dan ketidakberdayaan dalam menghadapi beragam permasalahan hidup yang tidak dapat di atasi dengan cara-cara rasional dan empiris, maka dimensi magic ini akan tetap menjadi sandaran sebagian masyarakat Banten dalam mengatasi setiap persoalan hidup yang dihadapi. Ini artinya bahwa sikap pragmatisme menjadi pendorong manusia, dalam hal ini masyarakat Banten, untuk tetap memperlakukan dan memanfaatkan ilmu-ilmu magic (termasuk didalamnya mantra) sebagai bagian dari praktik kepercayaan masyarakat yang menajdi bagian dari identitas kultural mereka.

\section{Jenis-jenis Mantra Masyarakat Banten}

Selama penelitian lapangan, peneliti berhasil mengumpulkan lebih dari 1000 doa dan mantra magic baik yang diperoleh dari kiai, ahli hikmah, dukun, maupun masyarakat umum, terutama yang sudah berusia di atas 50 tahun. Doa dan mantra tersebut memiliki fungsi, bentuk, dan bahasa yang beragam. Dari sekian banyak mantra yang tersebar dan masih diingat dalam memori kolektif masyarakat Banten, penulis mencoba memilah dan mengklasisifikasikannya menjadi 10 jenis berdasarkan fungsinya.

1. Doa dan mantra asihan atau pelet

Formula magic yang berfungsi untuk asihan ini adalah mantra yang paling banyak ditemukan di masyarakat Banten. Jenis formula magic ini diyakini dapat membangkitkan aura, wibawa dan karisma di pengguna. Dengan mewiridkan doa dan mantra jenis ini, diyakini akan banyak orang yang mencintai, mengagumi, dan merasa segan terhadap si pengguna. Berikut adalah beberapa contoh doa dan mantra yang berfungsi sebagai pelet atau asihan.

a. Nabi aku kang wawayangan

Item rupa sira

Sira rupa ku jenggi

Sang ratu landak dayak

Kikis sir kikis

Pangawasa ning isun 
Lalanang jagat

Si sapu jagat buana kabeh

(Siah, 60 thn, Cipayung, Padarincang, Serang, Banten)

b. Sir asap sir asih ti luhur sa usap rambut

ti handap sa usap dampal

nur cahayane kangjeung nabi Yusuf a.s.

Sing manjing ning awak isun

Lahaula wa la quwwata illa billah

(Mahfud, 50 thn, Ds.Pasirmae, Kec.Cipeucang, Pandeglang, Banten)

c. Niat isun amateka aji si arjuna

telur seja atina

sifat isun pan haning undur-undurani mati matane si...maring isun

beka mati wurung sida edan

wurung edan sida

welas sida asih atina si...maring isun

la ilaha illallah muhammadarrosulullah 'alaihi wa sallama

(Karyadi, 27 thn, Terate udik, Ds. Masigit, Cilegon, Banten)

d. Semar kuning, kuning-kuning kuraga sukma

kita bebondong sira arep glati sapa...

bokan glati semar kuning ...laka semar kuning

ya kita iki semar kuning

teka welas teka asih

Pendukune.......Ning kita

La ilaha illallah muhammadarrasululloh...

(Bara, 32 thn, Panimbang, Banten)

Mantra-mantra tersebut penulis kategorikan sebagai jenis mantra asihan atau pelet bukan hanya karena mantra itu memang diperlakukan atau digunakan oleh masyarakat untuk tujuan memikat lawan jenis, tetapi juga secara tekstual, ada kata-kata atau kalimat-kalimat yang mengandung makna asihan, seperti kata teka welas teka asih. Penggunaan nama-nama tertentu seperti Arjuna, dan nabi Yusuf memang dimitoskan dan diidentikkan sebagai tokoh-tokoh yang memiliki ketampanan dan mampu memikat lawan jenis karena aura dan wibawa yang mereka miliki.

2. Doa dan mantra magic kekuatan, kekebalan, dan ilmu kesaktian.

Jenis formula magic ini juga banyak ditemukan dan masih digunakan oleh sebagian masyarakat Banten. Berikut adalah beberapa contoh mantra 
untuk fungsi tersebut di atas:

a. Mantra kekuatan (untuk kekuatan tenaga dalam)

Sakukudung besi wulung

Sa kongkoyang beusi bodas

Cis ngicis beusi parasani

Ya isun prabu tujamalela

(Basri, 50 thn, Cilehem, Padarincang, Serang, Banten)

b. Mantra Ilmu Halimunan (ilmu dapat menghilang)

Isun ngewatek atiku jeneng siluman

aku ane ing sejerone

gedung wes kunci neng malaikat jibril

eng kang nutupi malaikat Mikail

eng kang ngaling ngalingi malaikat Isrofil

eng kang ngemuli malaikat Izroil

eng kang alingaken Allah

kang zumeneng nabi Muhammad

eng kang amayungi yahu qudrat irodat Allah

La ilaha illallah Muhammadarrasulullah.

(Suja'i, 65 thn, Desa gerem, Kec. Grogol, Kota Cilegon)

c. Mantra Kebal Golok

Asyhadu innahu syahadat isun

Innahu baginda Ali

bebalung wesi otot kulit kawat

ye isun macane neng Allah

sunggama mata sunggana mati

sungga getih lebuh hancur

jadi getih musne ilang tanpe kerane

di tampaku malaikat Jibril, malaikat Mikail, malaikat Isrofil, malaikat Izroil

Ples...., Plas...., Ples.....

(Suja'i, 65 thn, Desa gerem, Kec. Grogol, Kota Cilegon)

Sebagaimana jenis mantra untuk pelet dan asihan, pengkategorian tiga mantra di atas sebagai formula mantra untuk tujuan kekuatan, kekebalan, dan ilmu kesaktian juga tampak dari penggunaan beberapa kata yang terkandung dalam mantra yang menyimbolkan kekuatan. Kata-kata besi atau wesi dan kawat disimbolkan sebagai sebuah benda yang sangat kuat. Jadi dengan menyebut kata besi merefleksikan keinginan dan harapan manusia agar memiliki kekuatan tubuh sekuat besi dan kebal dari berbagai benda tajam. Penyebutan nama 
Sayidina Ali dan Prabu Tujamalela melambangkan tokoh-tokoh yang gagah, kuat, pemberani, dan memiliki kesaktian yang luar biasa.

3. Mantra untuk melakukan aktifitas sehari-hari

Dalam berbagai aktifitas sehari-hari seperti ketika berhias, mau tidur, mau bepergian, mau ke hutan, mau mancing, mengambil beras, mencuci beras, dan lain sebagainya, hampir selalu ada mantra atau doa yang dibaca. Mantra-mantra ini memiliki varian yang cukup banyak. Berikut adalah beberapa contoh mantra untuk aktifitas sehari-hari yang dibaca oleh sebagian masyarakat Banten.

a. Mantra Paranti Laleumpangan (Untuk bepergian)

Sang ratu basada

abdi bakasih rek liwat

(Aang Anharudin, 32 thn, Kp. Pasir Mindi Ds. Nambo Udik

Kec. Cikande Serang-Banten)

b. Mantra/Jampe Menta Lauk (Jampe Mancing)

Aki batara gangga nu ti girang

Aki batara gangga nu ti hilir

Aing menta ingon-ingon

Geura top

(Munaji, 40 thn, Ciomas, Serang, Banten)

Dari dua mantra tersebut di atas, terlihat bahwa di setiap tempat dan dalam setiap aktifitas manusia selalu ada makhluk penunggu (makhluk gaib) yang mesti dimintai izinnya ketika hendak melakukan sesuatu dan dimintai bantuannya agar setiap kegiatan dan aktifitas yang dilakukan oleh manusia bisa selamat dan berhasil.

4. Mantra untuk keselamatan dan perlindungan

Mantra untuk memohon keselamatan dan perlindungan juga banyak ditemukan di lapangan dengan beragam bentuk dan variasi. Berikut adalah beberapa contoh mantra untuk fungsi di atas:

a. Mantra Keselamatan Hidup (Mantra ini biasanya digunakan jika hendak merantau ke tempat yang jauh dari rumah agar selamat)

Cah wadung nu herang nu ngagolenggang

Nu ngalimung putih banyu lulut banyu runtut

Banyu anom banyu asih

Ka awaking arci nu ngaran ngajadi arca 
Ngarasia nu ngarupa

Aduh ambu nyeuri angeun

Meureun nyeuri angeun ngarasia kolot

Nur cahayaning pangeran

Ngalampuruk ningali manuk ngapung

Ngalangkarak ningali hayam kokotak

Reus ngindeng ka badan raga awaking

Putus rantunana akmasia deudeuh bau deudeuh banget

Ratu kumara datang

-Nya aing dewa pangencar

(Munawir, 23 thn, Cibaliung, Pandeglang, Banten)

b. Mantra/Jampe Menjauhkan Ular

Sembur alang-alang adas pulo sari

Disembur ore kepalang tapi gelis mati $3 x$

Salamun qoulan mirrabirrahim $(3 x)$

Salamun ala ufhin lil 'alamin ( $3 x)$

Ahklor/ular, lunge sire

Kiteki arep ngmbil suket mbokan kairis sire potol

Kite ki anak putune ki kernen

Demi Allah demi Rasulullah

Karena Allah Ta'ala.

(Miftah, 26 thn, Trumbu, Kasemen, Serang Banten)

Sebagaimana mantra dalam kategori keempat, mantra dalam kategori ini juga merefleksikan adanya keyakinan manusia atas makhluk-makhluk gaib yang dapat dimintai bantuannya untuk melindungi mereka dari berbagai bahaya. Penulis mengkategorikan ragam mantra ini dalam kategori mantra perlidungan dan keselamatan karena jenis mantra ini lebih menitikberatkan pada fungsi perlindungan atas keselamatan dari berbagai marabahaya. Sedangkan pada kategori keempat cenderng lebih pada harapan manusia atas keberhasilan suatu aktifitas dengan meminta bantuan makhluk-makhluk gaib.

5. Mantra untuk pengobatan

Ilmu pengobatan dengan menggunakan media ilmu magic juga banyak ditemukan di berbagai tempat di Banten. Berikut adalah beberapa contoh doa dan mantra untuk mengobati baik penyakit medis maupun non-medis:

a. Mantra Sawan (ketakutan karena melihat hantu atau karena kesurupan, biasanya untuk bayi dan anak-anak yang rewel/nangis terus) 
Bismillahirrohmanirrohim...

Sawan langlang

Sawan lingling

Ulah nyawan ka anak kuring

Rek nyawan ka anak anjing

(Halimah, 50 thn, Kp. Kareo Kulon, Desa Sukamanah Baros, Serang Banten)

b. Jampe Ngubaran Luka (mengobati luka)

Cipta herang acem kita

Asup ka sang hyang rasa

Pet kulipet otot rapet polo rapet

Pet rapet pet rapet pet rapet ku kersaning Allah

(Munawir, 23 thn, Cibaliung, Pandeglang, Banten)

Mantra jenis ini penulis kategorikan sebagai jenis mantra untuk pengobatan karena berdasarkan fungsi dan maknanya memang diperuntukkan bagi pengobatan penyakit, baik penyakit biasa yang dapat siobati dengan cara-cara medis, maupun penyakit non-medis. Secara tekstual, kata-kata yang digunakan pun menunjukkan fungsi tersebut, seperti kata-kata Ulah nyawan ka anak kuring, Rek nyawan ka anak anjing bermakna 'jangan membuat sawan (takut) anak saya, kalau mau, buat sawan anak anjing. Juga pada kata-kata Pet kulipet otot rapet polo rapet bermakna bahwa manusia berharap luka yang diakibtakan oleh benda tajam yang tadinya menganga, dapat sembuh dan rapat kembali seperti sediakala.

6. Mantra untuk pertanian

Sebagian masyarakat Banten yang memenuhi kebutuhan hidupnya dengan bertani atau berkebun, hasil panen melimpah menjadi harapan terbesar bagi mereka. Ketakutan dan kekhawatiran terhadap hasil panen yang kurang bagus atau hasil tanam mereka terkena hama memunculkan berbagai jenis mantra sebagai upaya untuk mencegah terjadiny agagal panen dan gagal tanam. Berikut adalah beberapa contoh mantra yang masih digunakan oleh sebagian masyarakat Banten, terutama petani:

a. Mantra mengusir tikus di sawah

Kempong maya dewa maya sing sapa

Ora weruh iki dudu papanganan sira

papanganan sira mah kuh ning gunung

La ilaha illallah

Muhammadurrasulullah 
(Saedah, 59 thn, Kp. Pangsor, Ds. Sagiang, Kec.Sepatan Timur, Tangerang, Banten)

b. Jampe tandur (biasanya digunakan ketika mau menanam atau menyemai padi)
Asyhadu sadat bumi
Bumi suci badan suka
Suka-suka ku panarima
Tarima ku ujud ning Allah
La ilaha illallah
Niat kula ngawinkeun sri ka bumi
La ilaha illallah
Muhammadurrasulullah
(Badriah, 40 thn, Ds. Senangsari, Serang, Banten)

Penulis mengkategorikan beberapa mantra sebagai jenis mantra untuk pertanian dengan alasan bahwa: pertama, seringkali mantra-mantra tersebut menyebut nama-nama Nyi Pohaci atau Sri (Dewi Sri) sebagai seorang dewa dalam kepercayaan Hindu yang disimbolkan sebagai dewa kemakmuran dan sebagai asal muasal adanya padi, oleh karenanya dianggap sebagai pelindung bagi tanaman (padi). Penyebutan kata-kata bumi juga merefleksikan harapan manusia agar bumi sebagai tempat untuk menanam berbagai jenis tumbuhan dapat memberikan keberkahan dan kesuburan sehingga menghasilkan panen yang melimpah.

7. Mantra untuk kelancaran dan kesuksesan usaha dan perdagangan

Masyarakat yang berprofesi sebagai pedagang seringkali merasa khawatir jika dagangannya tidak laku, atau kurang memberikan keuntungan yang maksimal. Sehingga untuk mengatasi kekhawatiran ini, mereka sering mendatangi para kiaihikmah atau dukun meminta ilmu magic tertentu baik dalam bentuk jimat, wafak, wiridan, ata doa dan mantra tertentu. Berikut adalah salah satu contoh mantra yang biasanya digunakan untuk kebutuhan ini:

Mantra panglaris (digunakan ketika berjualan/berdagang)

Panglarisan panglarisan

mapay subuh kotok kokok

anjang di jujung tongtung di teang

ngarumbuy loba pakayon

ngungsut kekesang sarangagenapi mongklang 
(Khoriunnisa, 23 thn, Serang Banten)

Banyak mantra yang penulis kategorikan sebagai jenis mantra untuk tujuan kelancaran dan kesuksesan usaha dan perdagangan karena fungsi dan penggunaannya oleh masyarakat yang memang digunakan untuk tujuan itu. Selain itu, adanya unsur-unsur bahasa (kata-kata) seperti penglarisan (pelarisan) dan subuh kotok kokok (kokok ayam pagi) menyimbolkan harapan manusia agar Yang Gaib membantunya agar dagangan mereka laris atau usahanya lancar, juga keharusan manusia agar segera beraktifitas dan bekerja keras yang dimulai sejak kokok ayam di pagi hari.

8. Mantra Kebatinan dan Karomah

Beberapa orang seringkali melakukan ritual tertentu untuk memperoleh ilmu kebatinan dan karomah ilmu magic tertentu, umumnya formula magic yang diwirid dalam bahasa Arab, tapi ada sebagian doa atau mantra dalam bahasa lokal (jangjawokan). Berikut adalah beberapa contoh mantra kebatinan atau karomah:

a. Mantra Ilmu Batin

Ya Allah ya Rabbi ya Rasulullah

kula abdi nyuhunkeun karomatna sesepuh Banten

nyuhunkun ilmu bathin

(Sarip, 50 tahun. Kresek Tangerang Banten)

b. Mantra memohon karomah

Kula minta syafaat mu'jizat kangjeng nabi Muhammad SAW

lan kula minta barokah karomah Syeikh Mujahidin Abdil Qadir Jaelani semoga sempet hadir

lan kula minta badan diisikaken karomah pencak jikarot

nomor siji sampai patang puluh jurus

minta jalan serta cepat

(Sarip, 50 tahun, Kresek Tangerang Banten)

Kategori ini penulis buat karena istilah karomah seringkali dimaknai oleh sebagian masyarakat Banten sebagai karunia Tuhan atas orang-orang pilihan (orang suci) dengan beragai kekuatan dan kelebihan luar biasa. Kebatian dan karomah yang penulis maksud di sini adalah ilmu kebatinan dan ilmu hikmat yang umumnya banyak dicari oleh para pelaku magic di Banten. 
9. Mantra untuk tujuan jahat

Selain untuk tujuan-tujua positif di atas, ada beberapa mantra yang ditujukan untuk tujuan negatif. Mantra jenis ini juga dimiliki oleh sebagian masyarakat Banten diantaranya:

a. Mantra Leunca (Untuk Membuat Perempuan Orgasme dari Jarak Jauh)

Ruruncang ruruncang ruruncang

Pang rurucangkeun awewe eta doang

Leunca nu di pencet

(Nida Amalia, 22 thn, Serang, Banten)

b. Mantra Paneluh Galunggung (untuk Mencelakai Orang)

Ratu teluh ti Galunggung

Sang Ratu cedacawal

Ratu teluh ti Gunung Agung

Sang Ratu murba Sakama

Sang Ratu Talaga Bodas

Nu kumawasa pusering talaga

Sang Ratu Cedacawal

-Nya aing Sang Ratu Cedacawal

Pur geni pur braja

Seuseup getihna

Cokcrok ototna

Sebet atina

Bedol tikorona

Sayab nyawana

Tuh Singsieunan si

(Aini, 47 thn, Ds.Kananga, Kec. Menes, Pandeglang Banten)

Penulis mengklasifikasikan jenis mantra ini sebagai mantra untuk tujuan jahat karena secara fungsional mantra-mantra ini memang digunakan untuk tujuan negatif seperti membuat orang sakit, membuat orang meninggal dengan cara-cara yang tidak lazim, maupun untuk menjahati perempuan baik-baik agar terangsang dan mengalami orgasme dengan cara-cara magic oleh orang-orang yang memiliki pikiran jahat. Kata-kata yang digunakan pun menyimbolkan makna jahat seperti pada kata-kata Cokcrok ototna, Sebet atina, Bedol tikorona, Sayab nyawan, yang artinya 'pecahkan ototnya, belah/sayat hatinya, jebol kerongkongannya, dan tarik nyawanya'.

10. Mantra untuk fungsi dan tujuan yang lain

Ada banyak mantra yang tidak dapat peneliti masukan dalam 9 kategori 
di atas, mantra-mantra ini umumnya untuk keperluan hajatan, penerang hati, untuk permainan, dan lain sebagainya. Berikut adalah beberapa contoh mantra untuk tujuan dan fungsi yang beragam:

a. Jampe -Nyarang Hujan

Bismillahirrohmanirrohim...

nini raspati jaya ning angin

embah buyut dalem jaya kusumah

(Dibaca $7 x$ sambil nahan nafas)

(Uyut Katmi, 98 thn, Cikeusal, Serang, Banten)

b.Jampe maen Bola

Katimur kabarat kaselatan jeung ka utara

sakabeh angin cicing di awak aing

lumpat kenceng tendangan kenceng

sundulan kenceng jeung jagaan gawang

aing yaa Mbah Buyut Bahrudin

Mbah Buyut Bahrudin...

Mbah Buyut Bahrudin

salam ka dewa-dewa langit

(dibaca sambil nginjek bumi $3 x$ )

(Munir, 34 thn, Cilehem, Padarincang, Serang, Banten)

Ada banyak ragam mantra yang tidak dapat penulis kategorikan dalam sembilan kategori di atas karena banyaknya fungsi dan tujuan dari mantramantra tersebut yang berbeda dengan 9 kategori sebelumnya. Oleh karena itu, untuk menyederhanakan ragam mantra yang tidak dapat masuk dalam salah satu dari 9 kategori tersebut, penulis membuat stau kategori lagi, yaitu kategori untuk tujuan dan fungsi lainnya. Yang masuk dalam kategori ini adalah mantra-mantra seperti untuk bermain sepak bola, untuk lari, untuk menghentikan atau menahan hujan, untuk hajatan, dan lain sebagainya.

\section{Mantra Banten sebagai Simbolisasi Kedekatan Hubungan Manusia dengan Makhluk Gaib}

Dalam batas tertentu, tradisi mantra Banten merupakan alternatif pranata sosial tradisional ketika pranata formal tidak mampu lagi mengakomodasi kepentingan mereka. Pemanfaatan mantra ini menjadi potret pola kehidupan pragmatis masyarakat Banten yang masih mempercayai hal-hal yang bersifat magic. Secara tipologis, formula magic di Banten terbagi dalam tiga jenis. Pertama 
adalah doa-doa yang diambil dari ayat-ayat al Quran maupun wiridan yang diambil dari Hadits, al Asma' al Husnah, dan lain sebagainya yang bersumber dari Islam yang diyakini memiliki efek dan daya magic. Kedua, mantra-mantra (jangjawokan) dalam bahasa Sunda, Jawa, atau Melayu yang diyakini memiliki pengaruh dan kekuatan magic. Ketiga adalah campuran eklektik dari doa-doa Islami dan mantra lokal.

Mantra adalah bagian paling penting dari praktik magic. Mantra adalah bagian magic yang bersifat gaib, yang diberikan dalam aktifitas magic dan hanya diketahui oleh praktisi atau ahli magic. Bagi para penduduk asli yang diteliti oleh Malinowski, ilmu magic berarti juga ilmu mantra, artinya bahwa orang yang ahli atau mengetahu mantra dia dapat dianggap sebagai dukun atau orang yang memiliki ilmu magic. Dari hasil analisisnya pada berbagai aksi tenung (witchcraft), akan selalu ditemukan bahwa pusat ritual akan berpusat pada mantra-mantra yang diucapkan. Menurutnya, formula magic (mantra) selalu menjadi 'the core of the magical performance' (Malinowski, 1954: 73).

Begitu juga di Banten, dalam setiap aktifitas magic pasti ada bacaanbacaan tertentu, baik itu berbentuk mantra maupun wiridan yang dibaca oleh ahli magic yang kadangkala maknanya tidak dipahami oleh orang biasa. Baik untuk mengobati penyakit maupun mengusir roh jahat ada doa-doa atau mantra-mantra tertentu yang dibacakan oleh ahli hikmah dan dukun yang diyakini mampu berpengaruh terhadap kondisi si pasien sesuai dengan tujuan yang diinginkan.

Mantra merupakan representasi dari keyakinan dan perilaku masyarakat penghayatnya. Mantra Banten diyakini masyarakat penghayatnya mampu menjembatani sejumlah kendala atau kebutuhan yang tidak dapat di atasi melalui kemampuan rasional berdasarkan perspektif manusia modern. Dengan demikian, mantra Banten ditempatkan oleh masyarakat penghayatnya sebagai salah satu bagian penting bagi mereka dalam menjalani beragam aktivitas hidupnya. Mantra Banten sebagai sebuah sarana pengikat hubungan manusia dengan kekuatan adikodrati tersebut pada kenyataannya tidak berdiri sendiri, ia hadir bersama-sama dengan pelaku magicnya, tindakan dan kepentingan magicnya, serta lingkungan magicnya. Dengan demikian, fungsi mantra yang terkandung di dalamnya pun secara potensial dapat ditunjukkan melalui keterikatan satu dengan yang lainnya menyangkut pelaku, tindakan kepentingan, dan lingkungan magicnya, tetapi juga menyangkut eksistensi mantra di masyarakat dalam perspektif religinya (Hudayat, 2007: 2).

Tradisi dan kepercayaan terhadap mantra tidak dapat dilepaskan dengan 
kehidupan religi masyarakat penghayatnya. Sejumlah bentuk ritual, seremonial, maupun aktivitas sehari-hari tidak dapat dilepaskan dari pembacaan mantra oleh masyarakat penghayatnya. Kehidupan religi yang dijalaninya akan menunjukkan bagaimana kepercayaan terhadap kekuatan adikodrati yang disaranai melalui mantra dapat diidentifikasi berdasarkan elemen-elemen yang melingkupinya. Sebagian masyarakat yang mengikatkan diri pada sejumlah pemanfaatan mantra, percaya bahwa mantra-mantra mempunyai kekuatan gaib yang berfungsi sebagai alat pengejawantahan ikatan masyarakat penghayat mantra dengan hal yang bersifat adikodrati. Oleh karenanya, masyarakat penghayat mantra begitu lekat dalam penyatuan dirinya dengan mantra dalam beragam kepentingannya. Namun demikian, tidak jarang sebagian masyarakat lainnya menempatkan pengikatan diri terhadap mantra dalam sejumlah aktivitas hidupnya sebagai suatu perbuatan yang irrasional atau bersifat takhayul. Dalam hal ini, Hudayat berpendapat bahwa keterhubungan mantra dengan penghayatnya, lingkungan magic, maupun dengan bukan penghayatnya merupakan indikasi-indikasi yang dapat ditinjau melalui persepktif fungsional. Mantra yang merupakan representasi kepercayaan masyarakat penghayatnya terhadap kekuatan adikodrati perlu ditinjau secara fungsional guna menemukan konsep fungsi di dalamnya (Hudayat, 2007: 3).

Fenomena seputar kepercayaan masyarakat, terutama yang menyangkut penilaian terhadap mantra begitu tampak pada jaman modern ini. Masyarakat luas mengenal adanya white magic dan black magic. Kolektif penghayat mantra mempercayai bahwa mantra menghasilkan kekuatan gaib. Mereka pun percaya bahwa mantra akan mampu menjawab hal-hal atau masalah-masalah yang ada di dalam kekuatan supranatural atau di luar jangkauan pemikiran dan kekuatan manusia pada umumnya. Dalam hubungannya dengan kenyataan di lapangan, tidak jarang white magic beralih peran menjadi black magic. Hal ini didasarkan kepada siapa dan bagaimana akibat yang ditimbulkan oleh mantra tersebut, mantra asihan dan pelet misalnya, dapat beralih tujuannya menjadi baik ketika pengguna mantra tersebut mendasarkan diri pada kesadaran akan tujuan baik yang akan dicapainya, misalnya bagi kepentingan keharmonisan rumah tangga. Dalam sebuah penelitian tentang dukun dan mantra menyatakan bahwa tidak selamanya guna-guna tergolong tidak baik. Menolong gadis supaya cepat dapat pasangan atau pun kawin, supaya seorang suami atau istri tidak menyeleweng, supaya perempuan yang berebut suami orang lain cerai atau pisah, merupakan kasus yang perlu ditolong dengan pemasangan guna-guna. Bagi kolektif penghayat mantra, kegiatan sehari-hari 
kerapkali diwarnai dengan pembacaan mantra demi tercapainya suatu tujuan, misalnya para petani ingin sawahnya subur, terhindar dari gangguan hama, hasil panen melimpah; para pedagang ingin dagangannya laris dan memperoleh laba besar; dan bermacam-macam tujuan lainnya dalam beragam aktivitas kehidupan masyarakat di dalamnya (Sianipar, 1989: 67).

Keberadaan mantra di masyarakat yang masih bertahan dan masih digunakan oleh sebagian masyarakat menunjukkan bahwa mantra masih dianggap sebagai kepercayaan yang sangat penting dalam kehidupan keseharian. Beragam jenis mantra masih tersimpan dalam memori kolektif masyarakat, khususnya di Banten. Meskipun sebagian orang sudah tidak mau lagi menggunakan mantra untuk memecahkan beragam masalah praktis dalam kehidupan mereka, dan menggantinya dengan bacaan-bacaan doa yang bersumber dari ayat-ayat al Quran, namun penggunaan mantra di masyarakat Banten masih berlangsung hingga saat ini. Sebagian masyarakat Banten masih membawa anak-anak mereka yang mau disapih (berhenti menyusu ASI) ke dukun,wong pinter (orang yang dianggap memiliki ilmu magic dan mantra), maupun ke orang-orang yang usianya sudah sangat tua. Tidak jarang mereka juga datang ke rumah dukun dan wong pinter untuk mengobati penyakit, untuk meminta pelet agar disukai oleh orang lain, untuk memperlancar usaha dan perdagangan dan lain sebagainya. Problem-problem praktis keseharian yang tidak dapat di atasi dengan cara-cara rasional seringkali diserahkan kepada orang-orang yang dianggap memiliki kemampuan supernatural. Hal ini tidak hanya berlaku pada masyarakat awam dan masyarakat perkampungan yang minim pendidikan, tapi juga pada orang-orang perkotaan yang berpendidikan tinggi. Ini artinya bahwa meskipun ilmu mantra sudah banyak ditinggalkan oleh masyarakat Banten, keberadaanya masih banyak dibutuhkan oleh mereka.

Mantra, salah satunya berfungsi sebagai alat atau media untuk membujuk atau memohon kepada agen-agen supernatural (baik ruh, jin, dan sejenisnya) yang memiliki kekuatan agar melindungi dan memberikan keselamatan bagi orang-orang yang berpotensi atau berada dalam bahaya. Selanjutnya dijelaskan juga fungsi mantra yang lain, yaitu sebagai lisensi untuk memanggil kembali kekuatan-kekuatan Tuhan dan Muhammad dan menjamin keamanan manusia (Bowen, 1993: 93-94). Artinya bahwa dengan menggunakan mantra yang menggunakan campuran ayat-ayat al Quran atau ada kalimat-kalimat yang memanggil nama Tuhan dan nabi Muhammad, sebenarnya mereka meyakini kekuatan dan Kemahakuasaan Tuhan dan juga mukjizat dan kehebatan nabi Muhammad yang memiliki kekuatan untuk mempengaruhi alam dan juga 
makhluk-makhluk gaib agar bekerja sesuai dengan apa yang dimohon oleh si penutur.

Mantra juga tidak dapat lepas dari konteks budaya masyarakat yang meyakininya. Antara mantra dan masyarakat mempunyai hubungan yang sangat erat. Artinya, mantra ada karena ada masyarakat pewarisnya. Masyarakat sangat meyakini bahwa pembacaan mantra merupakan wujud dari usaha untuk mencapai keselamatan dan kesuksesan. Keberadaan mantra di tengah masyarakat merupakan perwujudan suatu keyakinan atau kepercayaan. Kepercayaan tentang adanya suatu kekuatan gaib yang mendorong mereka untuk merealisasikan kekuatan tersebut ke dalam wujud nyata untuk memenuhi kebutuhan. Dalam hal ini, ditegaskan berpendapat bahwa mantra timbul dari suatu hasil imajinasi masyarakat dalam alam kepercayaan animisme. Masyarakat percaya akan adanya hantu, jin, setan, dan benda-benda keramat dan sakti (Hooykaas, 1952: 20). Hantu, jin, dan setan dalam anggapan mereka ada yang jahat dan selalu mengganggu kehidupan manusia, tetapi ada pula yang sifatnya baik. Makhluk gaib yang bersifat baik tersebut justru dapat membantu kegiatan manusia, seperti berburu, bertani, menangkap ikan, dan lain sebagainya. Hal tersebut hanya dapat terjadi apabila manusia menguasai mantra tertentu. Artinya, pembacaan suatu mantra tertentu dapat menimbulkan pengaruh magic (Hudayat, 2007: 87).

\section{Simpulan}

Pandangan dan kepercayaan terhadap dunia gaib (magic) tidak bisa dilepaskan dari corak pemikiran manusia, karena dunia magic merupakan salah satu dimensi lain yang hadir dalam pemikiran dan kepercayaan manusia. Bagi sebagian masyarakat Banten, kepercayaan terhadap mantra merupakan fenomena sosial yang menjadi bagian penting dari budaya masyarakat Banten.

Beragam jenis mantra yang tersebar dan masih tersimpan dalam memori kolektif masyarakat Banten menunjukkan bahwa sebagian masyarakat Banten masih meyakini dan percaya bahwa alam ini dikuasai oleh makhluk-makhluk gaib, dan makhluk-makhluk tersebut dapat dikontrol, dikuasai, diperintah, dan dimintai bantuannya untuk memenuhi kebutuhan praktis dan tujuan pragmatis manusia. Kepercayaan terhadap mantra juga menyimbolkan adanya kedekatan hubungan manusia dengan Yang Gaib yang dapat dimediasi melalui ragam formula magic atau mantra melalui ritual magic tertentu.

Kepercayaan terhadap mantra pada masyarakat Banten menjadikan tradisi magic menjadi bagian penting dalam beragam aktifitas sosial keagamaan 
mereka dan terus ditransmisikan dan diwariskan kepada generasi-generasi berikutnya. Banyaknya ahli magic baik kyai hikmah, ahli hikmah, maupun dukun dan para ahli magic lainnya yang terdapat di Banten menjadikan tradisi ini terus hidup dan terpelihara. Ini menjadi bukti bahwa tradisi magic dengan beragam mantra dan doa magicnya menjadi budaya yang terus hidup dan diyakini oleh sebagian masyarakat Banten.

Apa yang terjadi pada masyarakat Banten nampaknya sejalan dengan pendapat Anrosino dan Rudolf Otto bahwa kepercayaan dan agama berpusat kepada suatu konsep tentang hal yang gaib (mysterium) yang dianggap maha dahsyat (tremendum), dan keramat (sacer) oleh manusia, dan magic adalah sebuah elemn yang hampir ada dalam setiap agama dan kepercayaan. Ini artinya, secara antropologis, manusia akan terus berkomunikasi dan berinteraksi dengan makhluk-makhluk gaib sepanjang mereka memiliki keterbatasan dan ketidakberdayaan dalam menghadapi beragam masalah praktis dalam hidup mereka. Dan secara sosiologis, ini merefleksikan bahwa modernitas tidak selalu menghilangkan pengaruh ruang mistis dan magic dalam alam pikiran manusia dan dalam praktik keagamaan masyarakat karena secara fungsional, tradisi magic ini sangat berperan dalam keberlangsungan hidup masyarakat, terutama dalam hal pemenuhan spiritual dan pemenuhan kebutuhan pragmatis manusia.

\section{Daftar Pustaka}

Ambary, Hasan Muarif. 1996. "Islam dan Tradisi Budaya Banten." dalam Ruh Islam dan Budaya Bangsa. Aneka Budaya di Jawa, ed. Aswab Mahasin. Jakarta: Yayasan Festival Istiqlal, Bina Rena Pariwara.

Angrosino, Michael V., 2004. The Culture of the Sacred. Exploring the Anthropology of Religion. Illionis: Waveland Press, Inc.

Bowen, John R. 1993. Muslims through Discourse. Religion and Ritual in Gayo Society. Princeton, New Jersey: Princeton University Press.

Bruinessen, Martin van. 1995. Kitab Kuning, Pesantren dan Tarekat: Tradisi-Tradisi Islam di Indonesia. Bandung: Mizan.

Daud, Haron. 2004. Ulit Mayang: Kumpulan Mantra Melayu. cet-1. Selangor: Dawama Sdn.Bhd.

Frazer, J.G. 1933. The Golden Bough: A Study in Magic and Religion. London: Macmillan and CO. 
Geertz, Clifford. 1970. The Interpretation of Culture. New York: Basic Books.

Hartarta, Arif. 2010. Mantra Pengasihan. Rahasia Asamara dalam Klenik Jawa. Bantul: Kreasi Wacana.

Hudayat, Asep Y. dkk. 2007. "Tinjauan Fungsional Mantra Sunda di Daerah Cisurupan Garut”. Laporan Akhir Penelitian Dasar, Universitas Padjajaran Bandung.

Hooykaas, C. 1952. Penjedar Sastra. Terj. Ramoel Amar gelar Datuk Besar. Jakarta: J.B. Wolters.

Hutton, Webster. 1948. Magic: a Sociological Study. London: Oxford University Press.

Kaplan, David dan Robert A. 2002. Manner. Teori Budaya, Terj. Landung Simatupang. Yogyakarta: Pustaka Pelajar.

Malinowski, Bronislaw. 1955. Magic, Science and Religion and Other Essays with an Introduction. New York: Doubleday Anchor Book.

Mauss, Marcel. 2001. A General Theory of Magic. London \& N.Y.: Routledge Classics

O'Keefe, Daniel L. 1982. Stolen Lightning: the Social Theory of Magic. New York: Continuum.

Otto, Rudolf. 1936. The Idea of the Holy. an Inquiry into the non-Rational Factor in the Idea of the Divine and Its Relation to the Rational. Transl. by John W. Harvey. Oxford: Oxford University Press.

Pradipta, Budya. 2003. Hakikat dan Manfaat Mantra. Jakarta: Perpustakaan Nasional.

Saputra, Heru S.P. 2007. Memuja Mantra, Sabuk Mangir dan Jaran Goyang Masyarakat Suku Using Banyuwangi. Yogyakarta: LKIS.

Sianipar, T. at.al. Dukun, Mantra, dan Kepercayaan Masyarakat. Jakarta: Pustakarya Grafikatama,1989.

Sudjiman, Panuti. 1990. Kamus Istilah Sastra. Jakarta: UI Press

Tjandrasasmita, Uka. 2011. Banten Abad XV-XXI. Pencapaian Gemilang Penorehan 
Menjelang. Jakarta: Puslitbang Lektur dan Khazanah Keagamaan, badan Litbang dan Diklat Kementerian Agama RI.

Widodo, Wahyu. 1965. "Kearifan Lokal dalam Mantra Jawa", Proceeding the 4th International Conference on Indonesian Studies: "Unity, Diversity, and Future".

Yale, Robert A. 2003. Explaining Mantras. New York \& London: Routledge.

\section{Website:}

Zuhdi, Muhammad Harfin. "Tradisi Merari':Akulturasi Islam dan Budaya Lokal”, dalam http://doelmith.multiply.com/journal/item/34/ TRADISI_MERARIQ_ADAT_LOMBOK_AKULTURASI_ISLAM_ DAN_BUDAYA_LOKAL, (diakses 1 Juni 2012). 